\title{
3 Researchs Suare \\ COVID-19 related healthcare wastes management practices among Bangladeshi medical professionals
}

Md. Mostafizur Rahman ( $\nabla$ rahmanmm@juniv.edu )

Jahangirnagar University https://orcid.org/0000-0002-5290-3821

Mashura Shammi ( $\sim$ mashura926@juniv.edu )

Jahangirnagar University

Md. Liakath Ali

BRAC

Abu Sadat Moniruzzaman Khan

BRAC

Md. Abu Bakar Siddique

BRAC

Md Ashadudzaman

BRAC

Md. Bodrud-Doza

BRAC

G M Mostafizul Alam

BRAC

Shafi M Tareq

Jahangirnagar University

\section{Research Article}

Keywords: Biomedical waste, healthcare waste management, COVID-19, healthcare professionals, Knowledge, attitude, and practice (KAP)

Posted Date: June 7th, 2021

DOI: https://doi.org/10.21203/rs.3.rs-588383/v1

License: (c) (1) This work is licensed under a Creative Commons Attribution 4.0 International License. Read Full License 


\section{Abstract \\ Purpose}

Amidst the one year of COVID-19 the amount of healthcare waste generation manifolds in Bangladesh. This article aims to rapidly assess the knowledge, attitude, practice, and perception (KAPP) towards COVID-19 related healthcare wastes among Bangladeshi healthcare professionals.

\section{Methods}

This research was conducted following a multi-stage methodological approaches to achieve the desired objectives. A total of $300(=300)$ responses were collected from the healthcare professionals, including doctors, nurses, and relevant staff from the public and private medical hospitals and clinics.

\section{Results}

It was found that most of the respondents (83.7\%) know about the concerning issues of medical wastes and their types. Almost $90.0 \%(n=270)$ respondents agreed with the statement KS3, mentioned as 'medical waste of COVID-19 patients can be considered as infectious waste' and they are aware about the potential threat from the waste. It was also found that nearly $76.0 \%(n=228)$ of the respondents know about color coding for the segregation of medical waste. However, interestingly, $68.3 \%$ and $43.6 \%$ professionals have knowledge about the guidelines of medical waste management. Surprisingly, around $57.0 \%(n=171)$ respondents think that medical waste management adds an extra burden to their work. T-test indicates that demographic characteristics e.g., respondents' gender, age, occupation/job responsibility, work experience, and level of education, have a significant effect on the safe handling and disposal of biomedical waste.

\section{Conclusion}

Despite of having good knowledge about importance of safe handling and management of healthcare wastes Bangladeshi medical professionls have negative attitude and practices in the management of healthcare wastes.

\section{Introduction}

The healthcare waste generation depends on the facilities offered by the hospital, types of the hospital, healthcare waste management system, and the socioeconomic culture of the country (Ansari, Ehrampoush et al. 2019). Hospital solid waste generation rate and hospital solid waste composition in the developing countries are closely related to the environmental performance index and the GDP per capita (Ansari, Ehrampoush et al. 2019). However, due to the severe contagious nature of the COVID-19 virus, isolation wards, institutional quarantine centers, and home quarantines produce loads of biomedical waste (BMW) worldwide (llyas, Srivastava et al. 2020). Personal protective equipment (PPE), testing kits, surgical facemasks, and nitrile gloves are the major contributors to waste volume (llyas, Srivastava et al. 2020). Increased use of PPE and disposal can lead to secondary environmental disasters (Shammi and Tareq 2020).

Most countries, especially developing countries, struggle to manage the enormous surge of medical waste due to COVID-19 (Shammi, Behal et al. 2021). Due to the severe contagious nature of the COVID-19 human-to-human transmission predominantly caused by contact or cross-infection, airborne bioaerosol and droplet transmission, (Eslami and Jalili 2020, Karia, Gupta et al. 2020), fomite or surface transmission (Karia, Gupta et al. 2020). Personal protective equipment (PPE) is, therefore, an essential component for protecting healthcare workers, doctors, and other emergency service providers (Cook 2020, Islam, Safiq et al. 2020, Jones, Bleasdale et al. 2020). Moreover, our improved, hyper-hygienic way of life in the fear of transmission has conveniently shifted our behavioral patterns towards use of PPE (Vanapalli, Sharma et al. 2021). 
In a previous study in 2012, it was revealed that nearly one-third of medical doctors and nurses and two-thirds of technologists and cleaning staff had inadequate Knowledge, and about half of medical doctors (44.0\%) and cleaning staff (56.0\%) had poor practices of medical waste management in the healthcare centers in Bangladesh (Sarker, Harun-Or-Rashid et al. 2014). The level of Knowledge, attitude, practice and perception (KAPP) and associated factors among healthcare professionals and household residents are necessary towards practical and better biomedical waste management (Deress, Hassen et al. 2018, Mannocci, di Bella et al. 2020). Without active citizen participation and cooperation, virus-laden biomedical waste with the regular solid waste stream pose significant negative health and safety issues to sanitation workers (Sharma, Vanapalli et al. 2020). As a developing densely populated and highly resource-constrained country, Bangladesh failed to practice appropriate healthcare waste management (Khan, Cheng et al. 2019) despite having Medical waste management rules promulgated in 2008 (GoB 2008). Moreover, healthcare waste management facilities extensively lack proper waste segregation, collection, safe storage, transportation, and disposal (Khan, Cheng et al. 2019). Biomedical waste management generated both at hospitals, clinics, isolation centers requires special attention. Strategically a policy-concept shift along with proper planning and program can reform the existing healthcare waste management significantly and practically (Rahman et al. 2020).

Amid such vulnerable circumstances, the ill management of COVID-19 related healthcare waste urges special attention in the hospitals, clinics, and isolation centers for preventing the possibility of the 3rd wave of infection re-emerging. It is very crucial to have the proper Knowledge and attitude towards the COVID-19 related healthcare waste for its safe management among the healthcare professionals and practitioners. This article aims to rapidly assess the Knowledge, attitude, practice, and perception (KAPP) towards COVID-19 related healthcare wastes among Bangladeshi healthcare professionals for the first time in Bangladesh.

\section{Study Procedure}

This research was conducted from 20 July 2020 to 10 August 2020 following multi-stage methodological approaches to achieve the desired objectives. A total of $300(=300)$ responses were collected from the healthcare professionals, including doctors, nurses, and relevant staff from the public and private medical hospitals and clinics, to assess their KAPP on hospital healthcare waste management. Considering the healthcare waste management reports of Bangladesh from print and electronic media and literature review, the questionnaire was prepared. Both qualitative and quantitative measurement tools were adopted from scientifically accepted sources to perform a predefined set of activities, including selecting target groups, sampling, key informant interviews (KII), stakeholder consultations, data calculations, and analyses.

\subsection{The Questionnaire}

To assess the KAPP of the healthcare professionals, nine knowledge statements (KS), twelve attitude statements (AS), twelve practice statements (PS), and six perception statements (P) were identified. A total of 39 items was considered in the drafted questionnaire for the healthcare professionals. A five-point (1-5) Likert scale was used to identify the KAPP of each respondent regarding healthcare waste management that varied from strongly disagree to agree strongly.

\subsection{Data analysis}

The descriptive statistics (e.g. mean, median, mode, standard deviation, variance, skewness, kurtosis) were used to understand the general public and healthcare professionals KAPP on healthcare waste applying the Statistical Package for the Social Science (SPSS) v. 25.0. Datasets were further analyzed via t-tests and a one-way ANOVA test. Gender, age, occupation, and level of education was considered during these variations.

\subsection{Ethical consideration}

The consent of participants was taken, and they remained anonymous following the Declaration of Helsinki. Participants were informed of the specific purpose of the study. Only one response was recorded and the survey could be completed/terminated whenever they wished. 


\section{Results And Discussions \\ 3.1. Demographic profile}

A total of $300(=n)$ healthcare professionals including doctor, nurse, medical teacher, lab technician, cleaner, word boy etc. were attended the survey, among which the percentage of male and female was $57.3 \%(n=172)$ and $42.7 \%(n=128)$, and the composition of age groups were 18-25 years (21.3\%), 26-35 years (60.7\%), 36-50 years (14.7\%), $51-65$ years (3.0\%), and > 65 years $(0.3 \%)$ old respectively. It is found that the frequency of young participants, especially the age of $26-35$ years, is higher than the more senior and mid-age group, similar to the general participants. Almost all of the respondents who attended this survey are educated, and the level of education were found MBBS (59.7\%), MBBS and above (17.0\%), masters (7.0\%), bachelor (3.0\%), diploma (7.0\%), higher secondary (5.7\%) and secondary $(0.7 \%)$. In terms of occupation status, most of the respondents were doctors $(69.3 \%)$ although, other medical professionals like interns $(6.7 \%)$, community health workers (6.7\%), nurses (6.0\%), medical teachers (3.3\%), hospital cleaners $(2.7 \%)$, lab technicians $(1.7 \%)$, hospital management staffs $(1.0 \%)$, waste managers $(0.3 \%)$, word boys $(0.3 \%)$ and others $(2.0 \%)$ participated in the survey. Among the participants, more than half $(53.7 \% ; n=161)$ of the respondents works in medical college hospital, $29.3 \%$ in the general public hospitals, $10.0 \%$ in private clinics, $2.7 \%$ in technical institutes, $1.7 \%$ in the diagnostic centers, $0.7 \%$ in sample collection points and $2.0 \%$ in others institute or organizations (Fig. 2a). However, it is found that among the total eight administrative divisions of the country, almost half $(51.0 \% ; n=153$ ) of the respondents participated from Dhaka, $28.0 \%$ from Chattogram, $9.7 \%$ from Khulna, 5.3\% from Barisal, 2.3\% from Rangpur, 1.7\% from Mymensingh, 1.3\% from Rajshahi, and 0.7\% from Sylhet (Fig. 2b).

It is reported that almost $39.7 \%(n=119)$ of respondents have less than two years of work experience, $26.0 \%(n=78)$ have 2 to 5 years, $22.3 \%(n=67)$ have 6 to 10 years, and rest $12 \%(n=36)$ have more than ten years of work experiences in their respective field. In terms of the working hour per day, almost $44.0 \%$ of the respondents work 8 hours/day, whereas $30.0 \%$ work less than 8 hours/day and $26.0 \%$ more than 8 hours/day. It is found that, among the respondents, almost $64.0 \%(n=$ 192) professionals served COVID-19 patients.

\subsection{Knowledge, attitude, practices, and perception of healthcare waste management}

Healthcare wastes are a complex mixture of wastes produced by healthcare institutions and constitute a hazard to public health if handled inappropriately (Hassan et al., 2008). It also poses serious threats to environmental health and requires specific treatment and management before its final disposal (Alam et al., 2013; Rahman et al., 2020). Hence, this survey explored the Knowledge, attitude, and practices of healthcare waste handling, its impacts on human health, and environmental aspects (Fig. 3). The five-point Likert scale was applied to investigate the description of the statement related to the healthcare waste, where KS symbolizes knowledge statements, AS for attitude statement and PS for practice statement. The descriptive statistics regarding the Knowledge, attitude, practice and perception of the respondents are presented Table 1.

\subsubsection{Knowledge}

The unsafe disposal of healthcare waste is one of the most significant challenges facing developing countries like Bangladesh. To better manage healthcare waste, it is crucial to have adequate Knowledge regarding the healthcare waste, their disposal procedure, and consequences of unsafe disposal. To understand the healthcare professionals' depth of knowledge regarding healthcare waste, a set of statements are applied. It is found that most of the respondents (83.7\%) know about the concerning issues of medical waste and their types. However, still $16.3 \%(n=49)$ of respondents are not aware of the healthcare waste categories. The mean value of the statement KS1 is $4.19 \pm 0.91$ (Table 1), indicating that the people agreed with the statement. Again, the mean value of the statement KS2 regarding the hazardous medical waste generation is found on $4.31 \pm 1.01$. Around $85.0 \%(n=255)$ healthcare professionals who attended this survey are conscious about the generation of hazardous medical waste from their work stations like hospital, clinic and diagnostic centre etc. 
Generally, waste generated from the COVID-19 patients is infectious and can transmit the disease, hence should take proper care of disposal and management (WHO, 2020b). Almost $90.0 \%(n=270)$ respondents agreed with the statement KS3, mentioned as the 'medical waste of COVID-19 patients can be considered as infectious waste', where the mean value of the statement is found $4.59 \pm 0.91$ (Table 1). Infectious medical waste constitutes public health hazards, and it is essential to take special concern. It is found that $90.7 \%(n=272)$ of respondents are aware about the associated health hazards of medical waste. The mean value of the statement KS4 is $4.61 \pm 0.88$ (Table 1), indicating that the respondents approve of the statement. Usually, both general and hazardous wastes is generated from healthcare facilities. To segregate them from source, the Ministry of Health and Family Welfare (MOHFW) of Bangladesh introduced color coding system like green color bins for general waste (e.g., kitchen waste, tissue paper, package materials), red color bins infected plastic waste (e.g., syringe, gloves, plastic waste), yellow colour bins for infected waste (e.g., anatomical, surgical, discarded medicines), and blue color bins for glassware (e.g., antibiotic vials, metallic substances, glassware materials, and others) (MOHFW, 2011; Reza and Akter, 2018). It is found that, nearly $76.0 \%(n=228)$ of the respondents know about color coding for the segregation of medical waste (KS5), and the rest $24.0 \%$ are not aware about the color coding of waste bins. The mean value of the statement KS5 is found on $4.05 \pm 1.08$ (Table 1). Furthermore, the mean values of the statements KS6 to KS8 regarding the medical waste management rules, and guidelines range from 3.15 to 3.87 (Table 1), indicating the respondents are lacking in Knowledge of the statement's issues. Nearly $68.3 \%$ and $43.6 \%$ of professionals have Knowledge about the guidelines of medical waste management (KS6), and Bangladesh medical waste management rules 2008 (KS7), while 31.7\% ( $n=95)$ and $56.4 \%(n=169)$ respondents even don't know there is a guideline exist for the medical waste management in Bangladesh. However, extra care and adequate PPE should be used during the handling of medical waste. The mean value of the statement KS9 regarding this aspect is $4.62 \pm 0.90$ (Table 1). It is found that around $91.6 \%(n=275)$ of the respondents agreed with the statement and know about the necessity of PPE use and hand hygienic issues while handling medical wastes. The overall outcome is presented in a scale depicting the knowledge level along with attitude and practice (Fig. 3).

\subsubsection{Attitude}

To understand the respondent's attitude regarding the healthcare waste handling and safe disposal and management, a set of statements were selected and surveyed. The mean value of the attitude statement AS1 (proper medical waste handling is an important/crucial issue) is $4.62 \pm 0.81$ (Table 1), indicating that people agree with the statement. It is found that around $92.0 \%$ of the respondents (agree $16.3 \%$, strongly agree $75.7 \%$ ) agreed with the statement. Though safe disposal of hazardous medical waste management is crucial to reduce the environmental and public health hazards (Reza and Akter, 2018; Rahman et al., 2020), but around $57.0 \%(n=171)$ respondents think that, medical waste management add extra burden of work (AS2), with a mean of $3.51 \pm 1.30$ (Table 1). Besides, more than half $(52.7 \% ; n=3561$ ) of the attendees think that managing biomedical waste is a financial burden (AS3), where the mean value is found $3.40 \pm 1.21$ (Table 1). It is reported that improper disposal and management of biomedical waste may be infectious and can transmit disease (MOHFW, 2011; Reza and Akter, 2018; Ma et al., 2020). The mean value of the effects of improper disposal of biomedical waste related statements (AS4) is $4.64 \pm 0.88$ (Table 1), where $91.0 \%(n=273)$ of the respondents agreed with the statement. The findings of the healthcare professional attitude are different and better than the general public. However, around $87.6 \%(n=263)$ respondents agreed the statement mentioned as 'biomedical waste should be segregated into different categories at the point of generation (AS5)', where the mean value of the statement is found $4.39 \pm 0.92$ (Table 1). Improper disposal of healthcare waste will create environmental and public health threats, and now a matter of concern for the developing countries (Adogu et al., 2014; Somani et al., 2020). The mean value of the statements AS6 and AS7 regarding the importance of proper biomedical waste disposal are $4.59 \pm 0.87$, and $4.13 \pm 1.12$ (Table 1 ), where nearly $91.6 \%(n=275)$ and $76.0 \%(n=228)$ respondents agreed the statements. It is found that, around $11.0 \%$ of the respondents disagree and $13.0 \%$ neither agree nor disagree with the statement AS7, mentioned that, 'biohazardous wastes should be disinfected before disposal'. The mean value of the statement AS8 regarding the infectious waste storage issue is $4.53 \pm 0.85$ (Table 1), indicating people agree with the statement. Around $88.6 \%(n=266)$ respondents think infectious waste should not be stored for longer times in the healthcare unit. It is reported that, the haphazard disposal of medical waste creates environmental burden (e.g., soil, air and water pollution, clogging in municipal waterways, plastic pollution etc.), and increase the risk of risk of disease transmission (Fadare and Okoffo, 2020; Ma et al., 2020). The mean values of the statements AS9 and AS10 regarding the importance of 
safe handling and disposal of biomedical wastes are found $4.50 \pm 0.92$, and $4.58 \pm 0.86$ (Table 1), where almost $89.0 \%$ ( $n=$ $267)$ and $90.4 \%(n=271)$ respondents agreed the statements respectively. It is found that, around $91.3 \%(n=274)$ respondents think it is essential to take adequate measures to manage the escalating amount of biomedical waste (AS11), with a mean of the statement is $4.55 \pm 0.79$ (Table 1). However, to manage infectious healthcare waste properly, adequate training is necessary to expand the Knowledge of the employees. It is found that only $38.3 \%(115)$ attendees are being trained to handle biomedical waste amid COVID-19. The mean of the statement (AS12) is found $2.87 \pm 1.45$ (Table 1), indicating the people's unwillingness with the statement. So, proper training of the healthcare professionals regarding infectious waste handling and management, including the COVID-19 related waste, is now a time-demanding need.

\subsubsection{Practices}

To investigate the biomedical waste handling and management practices in healthcare organizations (e.g., hospital, medical college, clinic, diagnostic center etc.) by healthcare professionals, a set of statements were selected and surveyed. It is found that nearly $54.3 \%$ of respondents claimed to have a waste inventory system/logbook/datasheet, where the rest (45.7\%) people's organization did not maintain the logbook. However, the mean value of the statement (PS1) regarding the waste record is $3.41 \pm 1.21$ (Table 1$)$, where only $47.0 \%(n=141)$ attendees agreed with the statement. It is stated that proper segregation of medical waste at source is the golden rule of healthcare waste management (Adogu et al., 2014). Mixed-up hazardous and infectious waste with municipal waste may transmit the disease to waste workers (Ma et al., 2020). However, nearly half $(58.4 \%)$ of the respondents segregate the medical waste at source (PS2), with a mean of $3.61 \pm 1.18$ (Table 1). Around $41.7 \%(n=125)$ of the respondents claimed not to segregate the medical waste at the source point, which is a serious matter of concern.

Furthermore, $65.7 \%$ of the respondents said that their organizations have adequate facilities for temporary storage with primary treatment/disinfection plants for bio-medical waste. The mean value of the statement (PS3) regarding the disinfection of biomedical waste before disposal is found $3.38 \pm 1.26$ (Table 1). Nearly half $(50.7 \%)$ of the respondents claimed to use the disinfectant of biomedical waste before removal. To dispose of biomedical waste, the government has a guideline to use different bin colors for the segregation of waste at source (MOHFW, 2011). It is found that about $69.3 \%$ ( $n=$ 208) of respondents initially dispose of biomedical waste in a different color bin, where the mean of the statement PS4 is $3.87 \pm 1.17$ (Table 1). The mean value of the statements PD5 and PS6 regarding the PPE used for handling biomedical waste are $3.78 \pm 1.23$ and $3.62 \pm 1.24$ (Table 1). Around 64.0\% $(n=192)$ and 58.3\% $(n=175)$ respondents reported taking enough protective measures (PS5), and use PPE (PS6), while handling biomedical waste. However, nearly $57.4 \%(n=172)$ of respondents claimed to have a proper storage facility to collect medical waste at the workplace (PS7), with a mean of $3.56 \pm$ 1.24 (Table 1). But, around $42.6 \%$ respondent's organizations have no dedicated waste storage facilities. It is found that nearly $40.0 \%$ of the respondents reported having available cases of injuries during medical waste handling (PS8), with a mean value of $3.16 \pm 1.27$ (Table 1). So, proper precaution and protective measures (e.g., adequate PPE use) should be taken to handle the biomedical waste. Almost half $(52.3 \%)$ of the respondents reported that they are practicing the proper method for handling hazardous biomedical waste (PS9), where the mean value of the statement is found $3.47 \pm 1.23$ (Table 1). It is a matter of concern that till $47.7 \%(n=143)$ of the respondents are not handling the hazardous biomedical waste properly, it may be because of lack of awareness or adequate facilities. Approximately $57.0 \%(n=171)$ of respondents claimed to have an organizational active medical waste management system (PS10). The mean value of the statement PS10 is found $3.53 \pm$ 1.17 (Table 1). Again, $62.7 \%(n=188)$ of attendees said they had a dedicated team for biomedical waste handling and management. Many hospitals or healthcare organizations have no available facilities for the final disposal and management of generated hazardous medical waste. After proper segregation, they usually hand over the waste to other organizations for the last treatment. It is found that nearly half (52.3\%) respondents reported that their organization is connected with another organization for final treatment and disposal of generated medical waste (PS11), where the mean value of the statement is $3.41 \pm 1.28$ (Table 1). However, for the proper handling and management of medical waste, only $44.7 \%$ of the respondent's organization provided training to the employee and staff. So, adequate training should be provided for the healthcare professionals for the proper disposal and management of biomedical waste to reduce environmental and health hazards.

\subsubsection{Healthcare personnel perception on medical waste management}


To understand the healthcare professional's perception regarding better medical waste management, a set of statements is applied where the mean value of the statements (P1-P6) varies from 4.34-4.60 (Table 1), indicating that people agree with the statements. Around $88.6 \%(n=266)$ of respondents think that infectious waste generation increases during the pandemic, where the mean value of the statement (P1) is $4.51 \pm 0.92$ (Table 1). Again, the mean value of the statement (P2) regarding the waste management facilities is found at $4.34 \pm 0.88$ (Table 1). Approximately $84.0 \%(n=252)$ of personnel attend this survey, thinking that the existing biomedical waste management system is too fragile to deal with the increasing amount of waste amid COVID-19. It is well established that unsafe disposal of biomedical waste creates environmental and public health hazards (Rahman et al., 2020; Singh et al., 2020). It is found that nearly $89.7 \%(n=269)$ of respondents believe that improper management of biomedical waste increases the risk of health and environmental hazards (P3), where the mean value of P3 is found $4.51 \pm 0.82$ (Table 1$)$. Again, nearly $89.0 \%(n=267)$ of the respondents think that people are not aware of disposing of their healthcare waste, which creates risk for healthcare workers in the workplace (P4). The mean value of the statement (P4) is found at $4.55 \pm 0.79$ (Table 1), indicating the respondent's strength of agrees with the statement. Overall, in Bangladesh, medical waste management facilities are inadequate, and practices are not satisfactory. The mean value of the statement P5 regarding this issue is $4.34 \pm 0.85$ (Table 1$)$, where $85.6 \%(n=257)$ of the respondent's agreed with this statement. However, around $90.3 \%(n=272)$ of attendees think it is essential to introduce an integrated and inclusive plan with urgent implementation of interventions to cope with covid-19 related biomedical waste (P6), with a mean of $4.60 \pm 0.72$ (Table 1). Hence, it can be said that adequate and trained administration along with public awareness can improve the biomedical waste disposal and management system of the country.

\subsection{Relationship assessment of medical waste disposal with demographics}

T-test and one-way ANOVA test were performed to determine the relationship among demographic characteristics with medical waste disposal and management. As most healthcare professionals attended this survey have adequate education and work in almost a similar working environment, demographics have no significant impacts on the individual's waste management behavior, rather lack of institutional policy and awareness may affect the medical waste management. However, results of the T-test (Supplementary Table S1) indicate that demographic characteristics e.g., respondents' gender, age, occupation/job responsibility, work experience, and level of education, have a significant effect on the safe handling and disposal of biomedical waste.

Furthermore, one-way ANOVA is performed to evaluate the relationship among healthcare professional's Knowledge, attitude, practices, and perception regarding biomedical waste management with demographic items (Supplementary Table S2). It is found that respondent's occupation/job responsibility has significant effects on medical waste management. For instance, knowledge statements KS2 to KS5 and KS9 and attitude statements AS1, AS4, AS6, and AS11 are dependent variables on the respondents' occupation. From the results of the ANOVA test, it is found that the level of education and gender difference of the professionals has no effects on biomedical waste disposal and management. The age of the respondent is found another factor in medical waste disposal and management. Knowledge statements KS3-KS4, attitude statements AS1, AS4AS6, AS10-AS11 are seen as dependent variables on the age of the respondents. Again, the work experience of the respondents is also found significant in the attitude statement AS10, regarding the importance of safe handling and management of biomedical waste to reduce the risk of public health and the environment.

\section{Conclusions}

Overall, it can be said that, medical waste disposal and management is not at a satisfactory level. Lack of adequate/proper knowledge, poor attitude and inefficient practice of proper waste management are some of the problems militating against the proper hospital waste management. This study has exposed the need to improve the Knowledge via proper training about safe handling and management of medical waste. Therefore, it is essential to arrange adequate training regarding the biomedical waste management, to improve the Knowledge of the healthcare professionals and staff. 


\section{Declarations}

Funding: The research was supported by the Climate Change Program (CCP) of BRAC, Bangladesh.

Conflicts of interest/Competing interests (include appropriate disclosures): All the authors declare no conflits of interest.

Availability of data and material (data transparency): All the data are available to the authors and it is available upon request.

Code availability (software application or custom code): Not Applicable

Ethics approval (include appropriate approvals or waivers): Not Applicable

Consent to participate (include appropriate statements): All the participants were joined willingly and they had their full freedon to stay of withdraw for the the survey at any point of time.

Consent for publication (include appropriate statements): Not Applicable

\section{References}

1. Alam, M.Z., Islam, M.S., Islam, M.R., 2013. Medical waste management: a case study on Rajshahi City corporation in Bangladesh. J. Environ. Natural Resources, 6(1), 173-178.

2. GoB 2021. COVID-19 guideline. https://corona.gov.bd/storage/press-releases/June2020/CvOCZobyC4DkDsn1kPes.pdf Accessed 9 May 2021.

3. GoB 2008. Gadget SRO no 294/2008 Bangladesh medical waste management rules 2008. Department of Environment DoE/ Ministry of Environment, Forest, and Climate Change (MoEFCC)

4. Rahman, M.M., Bodrud-Doza, M., Griffiths, M.D., Mamun, M.A., 2020. Biomedical waste amid COVID-19: perspectives from Bangladesh. The Lancet Glob. Health, https://doi.org/10.1016/S2214-109X(20)30349-1.

5. Hassan, M.M., Ahmed, S.A., Rahman, K.A. and Biswas, T.K., 2008. Pattern of medical waste management: existing scenario in Dhaka City, Bangladesh. BMC Pub. Health, 8, 36 doi:10.1186/1471-2458-8-36.

6. Ma, Y., Lin, X., Wu, A., Huang, Q., Li, X., Yan, J., 2020. Suggested guidelines for emergency treatment of medical waste during COVID-19: Chinese experience. Waste Dispos. Sustain. Energy, 2, 81-84.

7. MoHFW, 2011. Environmental Assessment and Action Plan for Health, Population and Nutrition Sector Development Program. Ministry of Health and Family Welfare, Dhaka, Bangladesh. Assessed on August 21, 2020; from: http://www.mohfw.gov.bd/index.php?option=com_docman\&task=doc_download\&gid=359\&lang=en.

8. Singh, N., Tang, Y., and Ogunseitan, O.A., 2020. Environmentally sustainable management of used personal protective equipment. Environ. Sci. Technol., https://dx.doi.org/10.1021/acs.est.0c03022.

9. Ansari, M., M. H. Ehrampoush, M. Farzadkia and E. Ahmadi (2019). "Dynamic assessment of economic and environmental performance index and generation, composition, environmental and human health risks of hospital solid waste in developing countries; A state of the art of review." Environ Int 132: 105073.

10. Cook, T. M. (2020). "Personal protective equipment during the coronavirus disease (COVID) 2019 pandemic - a narrative review." Anaesthesia 75(7): 920-927.

11. Deress, T., F. Hassen, K. Adane and A. Tsegaye (2018). "Assessment of Knowledge, Attitude, and Practice about Biomedical Waste Management and Associated Factors among the Healthcare Professionals at Debre Markos Town Healthcare Facilities, Northwest Ethiopia." J Environ Public Health 2018: 7672981.

12. Eslami, H. and M. Jalili (2020). "The role of environmental factors to transmission of SARS-CoV-2 (COVID-19)." AMB Express 10(1): 92.

13. Ilyas, S., R. R. Srivastava and H. Kim (2020). "Disinfection technology and strategies for COVID-19 hospital and biomedical waste management." Sci Total Environ 749: 141652. 
14. Islam, S. M. D., M. B. Safiq, M. Bodrud-Doza and M. A. Mamun (2020). "Perception and Attitudes Toward PPE-Related Waste Disposal Amid COVID-19 in Bangladesh: An Exploratory Study." Front Public Health 8: 592345.

15. Jones, R. M., S. C. Bleasdale, D. Maita, L. M. Brosseau and C. D. C. P. E. Program (2020). "A systematic risk-based strategy to select personal protective equipment for infectious diseases." Am J Infect Control 48(1): 46-51.

16. Karia, R., I. Gupta, H. Khandait, A. Yadav and A. Yadav (2020). "COVID-19 and its Modes of Transmission." SN Compr Clin Med: $1-4$.

17. Khan, B. A., L. Cheng, A. A. Khan and H. Ahmed (2019). "Healthcare waste management in Asian developing countries: A mini review." Waste Manag Res 37(9): 863-875.

18. Mannocci, A., O. di Bella, D. Barbato, F. Castellani, G. La Torre, M. De Giusti and A. D. Cimmuto (2020). "Assessing knowledge, attitude, and practice of healthcare personnel regarding biomedical waste management: a systematic review of available tools." Waste Manag Res 38(7): 717-725.

19. Sarker, M. A., M. Harun-Or-Rashid, T. Hirosawa, M. S. Abdul Hai, M. R. Siddique, J. Sakamoto and N. Hamajima (2014). "Evaluation of knowledge, practices, and possible barriers among healthcare providers regarding medical waste management in Dhaka, Bangladesh." Med Sci Monit 20: 2590-2597.

20. Shammi, M., A. Behal and S. M. Tareq (2021). "The Escalating Biomedical Waste Management To Control the Environmental Transmission of COVID-19 Pandemic: A Perspective from Two South Asian Countries." Environ Sci Technol 55(7): 4087-4093.

21. Shammi, M. and S. M. Tareq (2020). "Environmental Catastrophe of COVID-19: Disposal and Management of PPE in Bangladesh." Glob Soc Welf: 1-4.

22. Sharma, H. B., K. R. Vanapalli, V. S. Cheela, V. P. Ranjan, A. K. Jaglan, B. Dubey, S. Goel and J. Bhattacharya (2020). "Challenges, opportunities, and innovations for effective solid waste management during and post COVID-19 pandemic." Resour Conserv Recycl 162: 105052.

23. Vanapalli, K. R., H. B. Sharma, V. P. Ranjan, B. Samal, J. Bhattacharya, B. K. Dubey and S. Goel (2021). "Challenges and strategies for effective plastic waste management during and post COVID-19 pandemic." Sci Total Environ 750: 141514.

\section{Tables}

Table 1. Descriptive statistics of the Knowledge, attitude, practices and perception of medical waste disposal and management of healthcare professionals $(n=300)$ 


\begin{tabular}{|c|c|c|c|c|c|c|c|c|c|c|}
\hline Items & Min. & Max. & Mean & $\begin{array}{l}\text { Std. } \\
\text { Error } \\
\text { of } \\
\text { Mean }\end{array}$ & Median & Mode & $\begin{array}{l}\text { Std. } \\
\text { Dev. }\end{array}$ & Variance & Skewness & Kurtosis \\
\hline \multicolumn{11}{|c|}{ Knowledge statements } \\
\hline $\begin{array}{l}\text { I know about } \\
\text { medical waste } \\
\text { and its types } \\
\text { (KS1) }\end{array}$ & 1 & 5 & 4.19 & 0.05288 & 4 & 5 & 0.91583 & 0.839 & -1.287 & 1.628 \\
\hline $\begin{array}{l}\text { Our health } \\
\text { facilities } \\
\text { generate } \\
\text { medical waste } \\
\text { (KS2) }\end{array}$ & 1 & 5 & 4.31 & 0.0588 & 5 & 5 & 1.01851 & 1.037 & -1.684 & 2.362 \\
\hline $\begin{array}{l}\text { Medical waste } \\
\text { of COVID-19 } \\
\text { patients can be } \\
\text { considered as } \\
\text { infectious } \\
\text { waste (KS3) }\end{array}$ & 1 & 5 & 4.59 & 0.05243 & 5 & 5 & 0.9081 & 0.825 & -2.495 & 5.728 \\
\hline $\begin{array}{l}\text { There are } \\
\text { health hazards } \\
\text { associated with } \\
\text { medical waste } \\
\text { (KS4) }\end{array}$ & 1 & 5 & 4.61 & 0.05081 & 5 & 5 & 0.88008 & 0.775 & -2.551 & 6.112 \\
\hline $\begin{array}{l}\text { I know about } \\
\text { colour coding } \\
\text { segregation of } \\
\text { medical waste } \\
\text { (KS5) }\end{array}$ & 1 & 5 & 4.05 & 0.06282 & 4 & 5 & 1.08815 & 1.184 & -1.085 & 0.383 \\
\hline $\begin{array}{l}\text { We have a } \\
\text { guideline to } \\
\text { manage the } \\
\text { medical waste } \\
\text { (KS6) }\end{array}$ & 1 & 5 & 3.87 & 0.06532 & 4 & 5 & 1.13129 & 1.28 & -0.838 & -0.083 \\
\hline $\begin{array}{l}\text { I know about } \\
\text { the Bangladesh } \\
\text { medical waste } \\
\text { management } \\
\text { rules } \quad 2008 \\
\text { (KS7) }\end{array}$ & 1 & 5 & 3.15 & 0.07875 & 3 & 3 & 1.36395 & 1.86 & -0.194 & -1.138 \\
\hline $\begin{array}{lr}\text { I know about } \\
\text { the } \\
\text { guideline } \\
\text { manage to } \\
\text { medical waste } \\
\text { of COVID-19 } \\
\text { (KS8) }\end{array}$ & 1 & 5 & 3.37 & 0.08042 & 4 & 4 & 1.39299 & 1.94 & -0.458 & -1.033 \\
\hline $\begin{array}{l}\text { All those who } \\
\text { handle medical } \\
\text { waste should } \\
\text { wear } \\
\text { appropriate } \\
\text { PPE } \\
\text { perform hand } \\
\text { hygiene after } \\
\text { removing it } \\
\text { (KS9) }\end{array}$ & 1 & 5 & 4.62 & 0.05199 & 5 & 5 & 0.90046 & 0.811 & -2.781 & 7.33 \\
\hline \multicolumn{11}{|c|}{ Attitude statements } \\
\hline $\begin{array}{l}\text { Proper medical } \\
\text { waste handling } \\
\text { is an }\end{array}$ & 1 & 5 & 4.62 & 0.04683 & 5 & 5 & 0.81104 & 0.658 & -2.608 & 7.088 \\
\hline
\end{tabular}




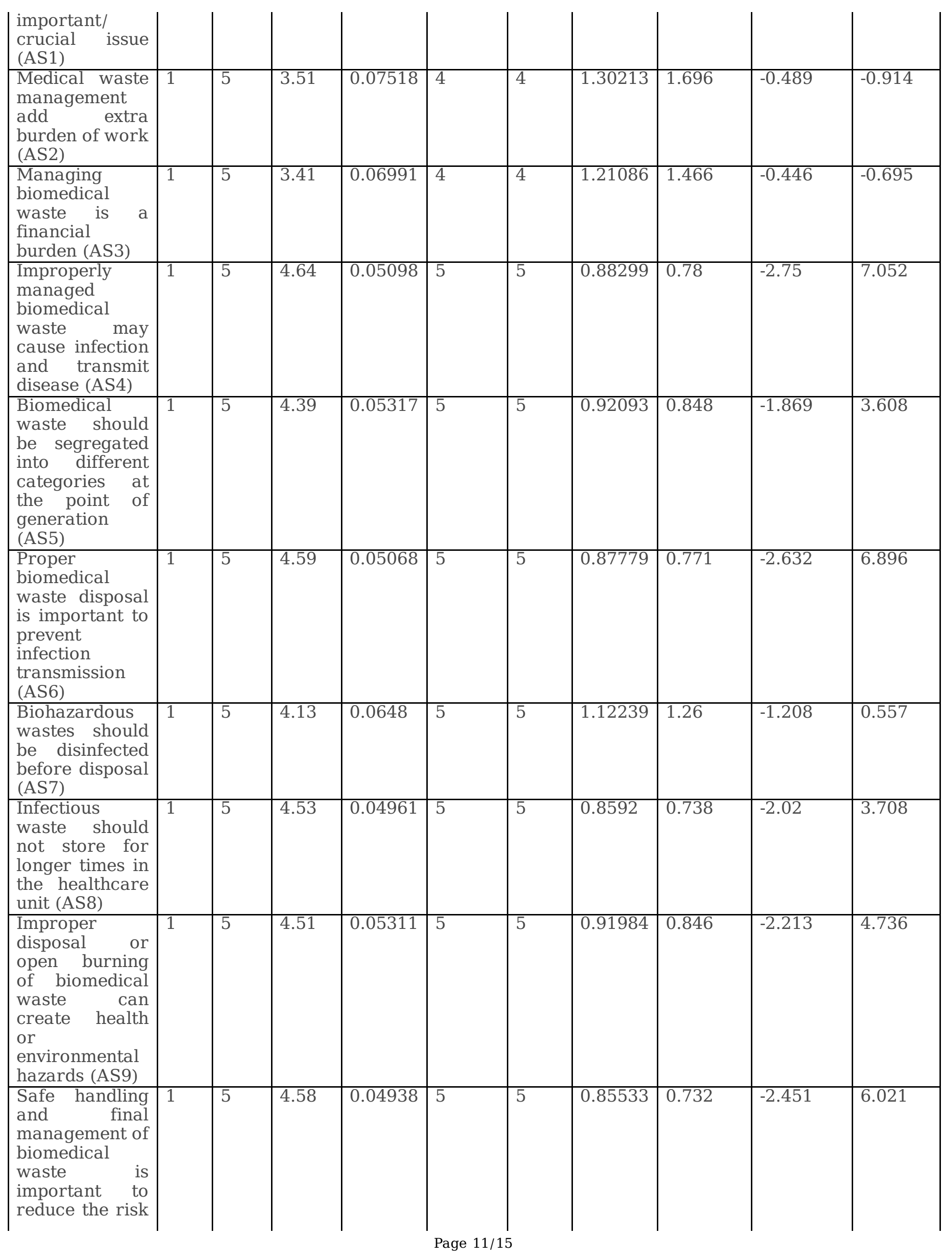




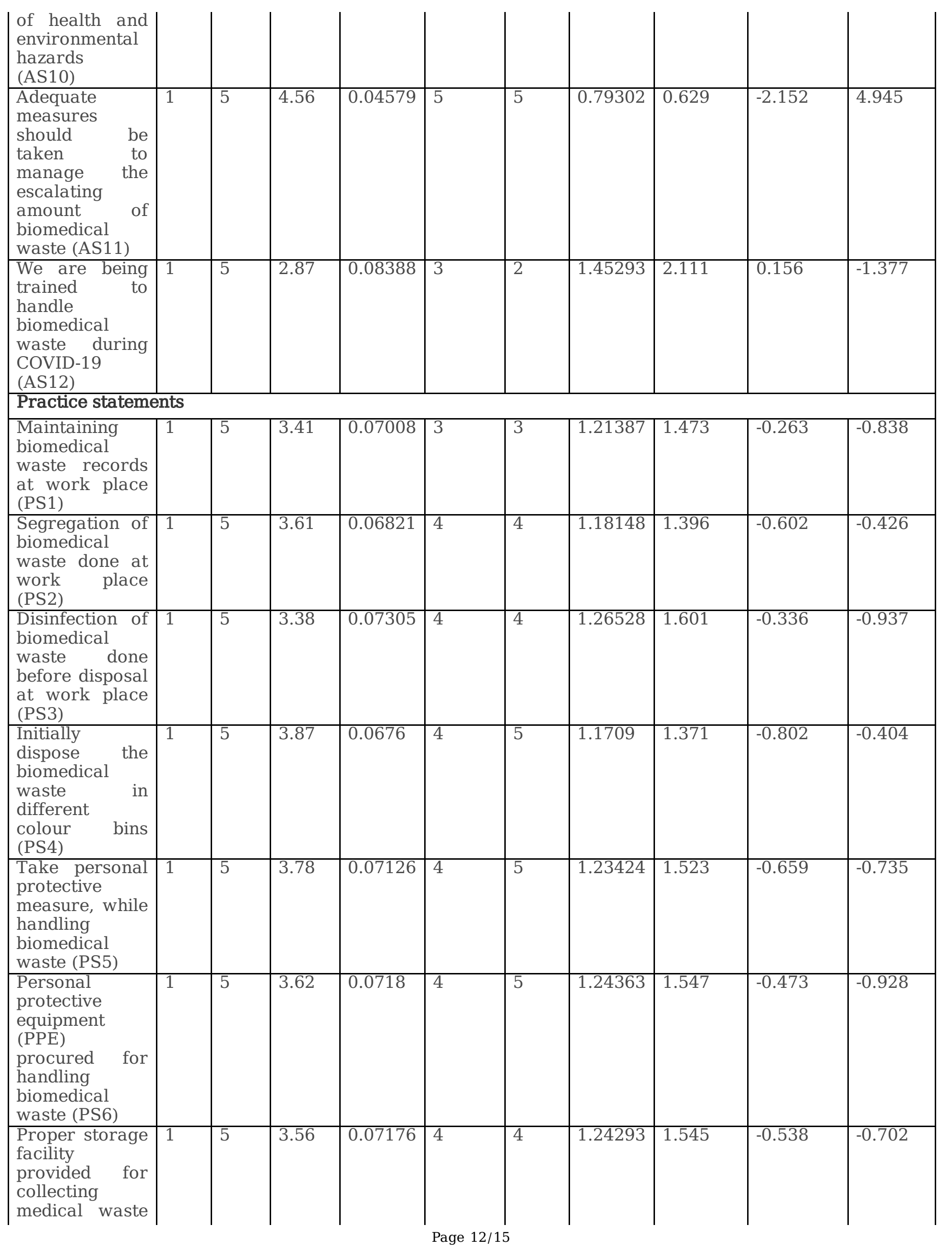




\begin{tabular}{|c|c|c|c|c|c|c|c|c|c|c|}
\hline $\begin{array}{l}\text { at work place } \\
\text { (PS7) }\end{array}$ & & & & & & & & & & \\
\hline $\begin{array}{l}\text { Any record } \\
\text { available for } \\
\text { injuries related } \\
\text { to medical } \\
\text { waste (PS8) }\end{array}$ & 1 & 5 & 3.16 & 0.07363 & 3 & 3 & \begin{tabular}{|l|}
1.27534 \\
\end{tabular} & 1.626 & -0.137 & -0.949 \\
\hline $\begin{array}{l}\text { Practicing } \\
\text { proper method } \\
\text { for handling } \\
\text { hazardous } \\
\text { biomedical } \\
\text { waste (PS9) }\end{array}$ & 1 & 5 & 3.47 & 0.07089 & 4 & 4 & \begin{tabular}{|l|}
1.22779 \\
\end{tabular} & 1.507 & -0.345 & -0.908 \\
\hline $\begin{array}{l}\text { We have our } \\
\text { own active } \\
\text { medical waste } \\
\text { management } \\
\text { system (PS10) }\end{array}$ & 1 & 5 & 3.53 & 0.06733 & 4 & 4 & \begin{tabular}{|l|}
1.16623 \\
\end{tabular} & 1.36 & -0.59 & -0.383 \\
\hline $\begin{array}{l}\text { Connected with } \\
\text { other } \\
\text { organization } \\
\text { for final } \\
\text { treatment and } \\
\text { disposal of } \\
\text { generated } \\
\text { medical waste } \\
\text { (PS11) }\end{array}$ & 1 & 5 & 3.41 & 0.07398 & 4 & 4 & 1.28135 & 1.642 & -0.442 & -0.824 \\
\hline $\begin{array}{l}\text { Training } \\
\text { provided on } \\
\text { medical waste } \\
\text { management } \\
\text { (PS12) }\end{array}$ & 1 & 5 & 3.21 & 0.07853 & 3 & 5 & \begin{tabular}{|l|}
1.36019 \\
\end{tabular} & 1.85 & -0.163 & -1.18 \\
\hline Perception state & mer & & & & & & & & & \\
\hline $\begin{array}{l}\text { More } \\
\text { infectious } \\
\text { waste are } \\
\text { generating } \\
\text { during the } \\
\text { pandemic (P1) }\end{array}$ & 1 & 5 & 4.52 & 0.0531 & 5 & 5 & 0.91971 & 0.846 & -2.114 & 3.913 \\
\hline $\begin{array}{l}\text { Existing } \\
\text { biomedical } \\
\text { waste } \\
\text { management } \\
\text { system is } \\
\text { fragile to deal } \\
\text { with the } \\
\text { increasing } \\
\text { amount of } \\
\text { waste (P2) }\end{array}$ & 1 & 5 & 4.34 & 0.05078 & 5 & 5 & \begin{tabular}{|l|}
0.87957 \\
\end{tabular} & 0.774 & -1.404 & 1.869 \\
\hline $\begin{array}{l}\text { Improper } \\
\text { management of } \\
\text { biomedical is } \\
\text { waste } \\
\text { increasing the } \\
\text { risk of health } \\
\text { and } \\
\text { environmental } \\
\text { hazards (P3) }\end{array}$ & 1 & 5 & 4.51 & 0.04757 & 5 & 5 & \begin{tabular}{|l|}
0.82386 \\
\end{tabular} & 0.679 & -1.958 & 3.872 \\
\hline $\begin{array}{l}\text { People are not } \\
\text { aware of } \\
\text { disposing their } \\
\text { healthcare } \\
\text { waste creating }\end{array}$ & 1 & 5 & 4.55 & 0.04581 & 5 & 5 & 0.79347 & 0.63 & -1.924 & 3.564 \\
\hline
\end{tabular}




\begin{tabular}{|c|c|c|c|c|c|c|c|c|c|c|}
\hline $\begin{array}{l}\text { risk for the } \\
\text { healthcare } \\
\text { workers in } \\
\text { workplace (P4) }\end{array}$ & & & & & & & & & & \\
\hline $\begin{array}{l}\text { In Bangladesh, } \\
\text { medical waste } \\
\text { management } \\
\text { facility/ } \\
\text { practice is } \\
\text { inadequate in } \\
\text { terms } \\
\text { capacity and } \\
\text { technology } \\
\text { (P5) }\end{array}$ & 1 & 5 & 4.34 & 0.04945 & 5 & 5 & 0.85645 & 0.734 & \begin{tabular}{|l|}
-1.391 \\
\end{tabular} & 1.883 \\
\hline $\begin{array}{lr}\text { Need an } \\
\text { integrated and } \\
\text { inclusive plan } \\
\text { with urgent } \\
\text { implementation } \\
\text { of } \\
\text { interventions } \\
\text { to cope with } \\
\text { covid-19 } \\
\text { related bio- } \\
\text { medical waste } \\
\text { (P6) }\end{array}$ & 1 & 5 & 4.61 & 0.04165 & 5 & 5 & 0.72136 & 0.52 & -1.885 & 2.965 \\
\hline
\end{tabular}

\section{Figures}

\section{Image not available with this version}

\section{Figure 1}

Figure not available with this version.

\section{Diagn Sampli}

Clinic, ostic ng Others, $10 \%$ centerspoints, $2 \%$

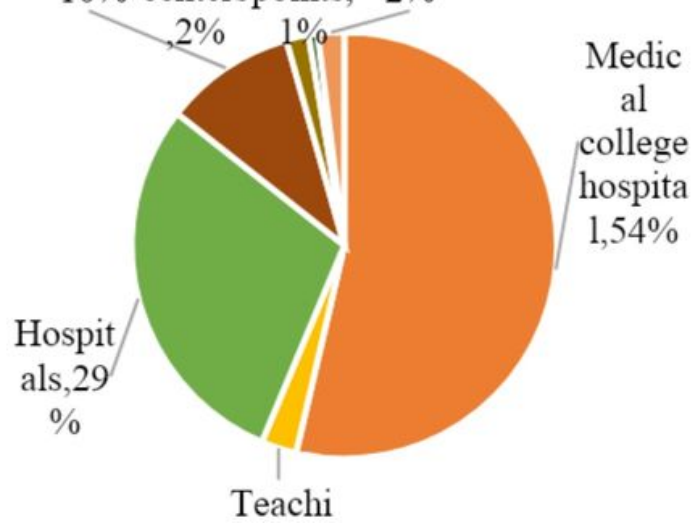

BarisaKhuln

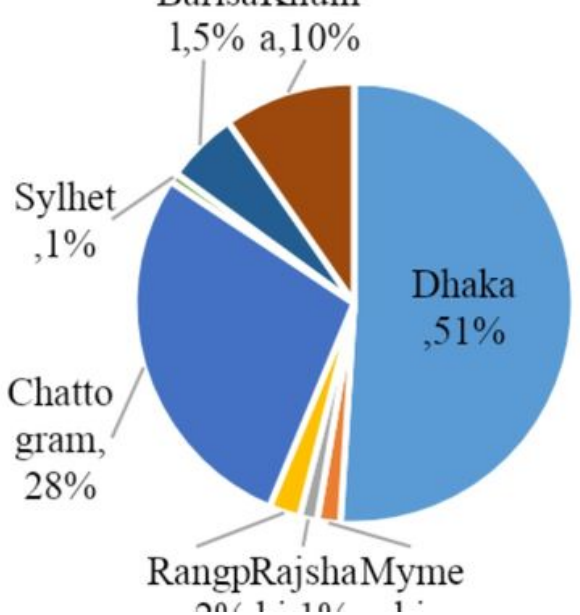

Figure 2 
Diagram showing the proportion of the respondents (a) working station (b) from different division of the country
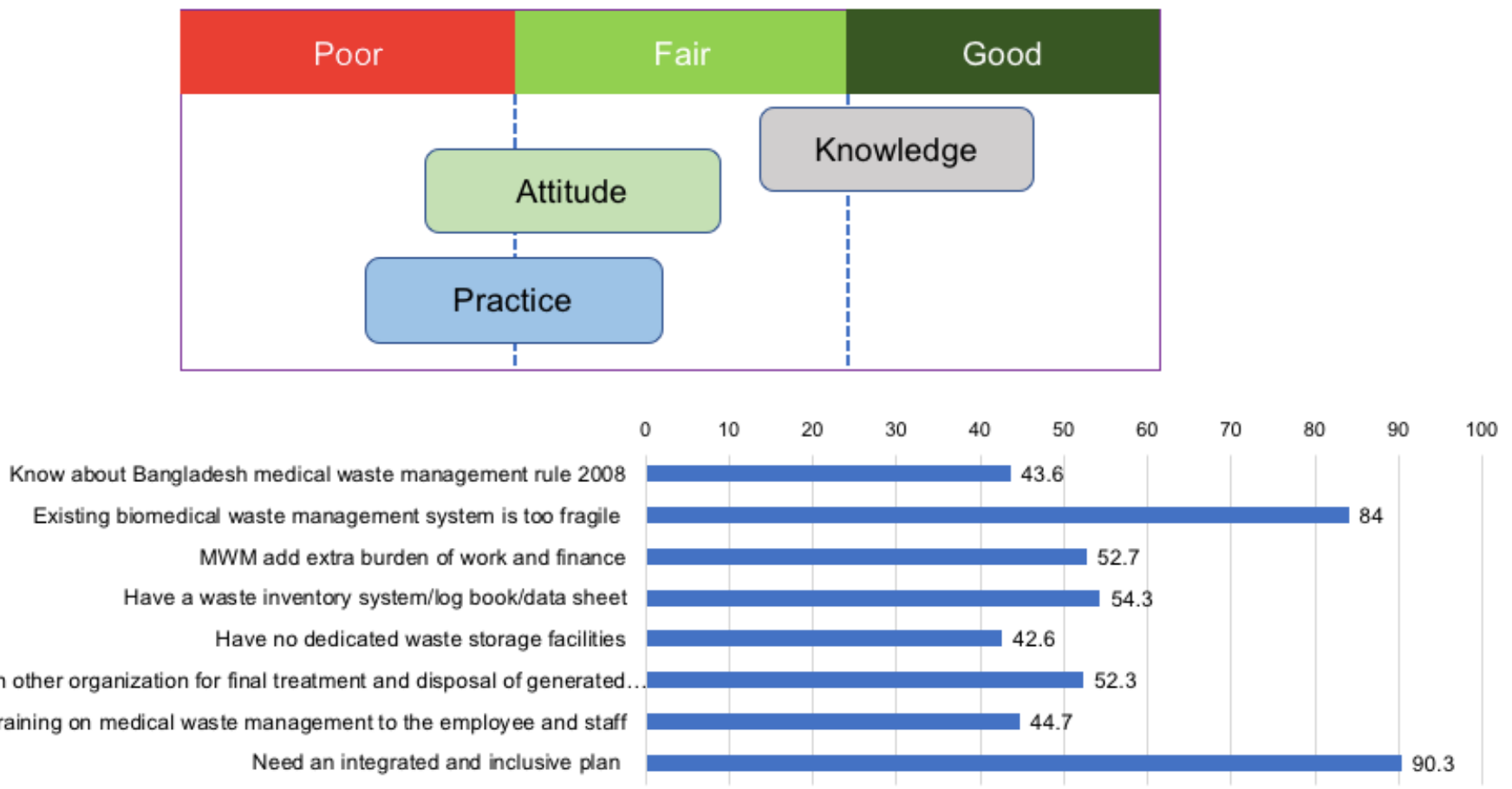

\section{Figure 3}

Knowledge, attitude, and practice of healthcare professionals towards healthcare/medical waste management.

\section{Supplementary Files}

This is a list of supplementary files associated with this preprint. Click to download.

- SupplementaryDatahealthcare.docx 